\title{
Breast cancer screening in the Czech Republic: time trends in performance indicators during the first seven years of the organised programme
}

\author{
Ondrej Majek1, Jan Danes², Miroslava Skovajsova ${ }^{3}$, Helena Bartonkova ${ }^{4}$, Lucie Buresova$^{1}$, Daniel Klimes ${ }^{1}$,
} Petr Brabec ${ }^{1}$, Pavel Kozeny ${ }^{5}$ and Ladislav Dusek ${ }^{1 *}$

\begin{abstract}
Background: The Czech Breast Cancer Screening Programme (CBCSP) was initiated in September 2002 by establishing a network of accredited centres. The aim of this article is to describe progress in the programme quality over time after the inception of the organised programme.
\end{abstract}

Methods: The CBCSP is monitored using an information system consisting of three principal components: 1) the national cancer registry, 2) a screening registry collecting data on all screening examinations, further assessments and final diagnoses at accredited programme centres, and 3) administrative databases of healthcare payers. Key performance indicators from the European Guidelines have been adopted for continuous monitoring.

Results: Breast cancer incidence in the Czech Republic has steadily been increasing, however with a growing proportion of less advanced stages. The mortality rate has recently stabilised. The screening registry includes 2,083,285 records on screening episodes between 2002 and 2008. In 2007-2008, 51\% of eligible women aged 45-69 were screened. In 2008, the detection rates were 6.1 and 3.7 per 1,000 women in initial and subsequent screening respectively. Corresponding recall rates are $3.9 \%$ and $2.2 \%$, however, it is necessary to pay attention to further assessment performed during the screening visits. Benign to malignant open biopsy ratio was 0.1. Of invasive cases detected in screening, 35.6\% was less than $10 \mathrm{~mm}$ in diameter. Values of early performance indicators, as measured by both crude and standardized estimates, are generally improving and fulfil desirable targets set by European Guidelines.

Conclusions: Mammography screening in the Czech Republic underwent successful transformation from opportunistic prevention to an organised programme. Values of early indicators confirm continuous improvement in different aspects of process quality. Further stimulation of participation through invitation system is necessary to exploit the full potential of screening mammography at the population level.

\section{Background}

Breast cancer is the most frequent malignant neoplasm in women worldwide [1]. In the past, its incidence and mortality in Central and Eastern European countries were significantly lower than in Western Europe. Yet recent changes in reproductive behaviour of women accompanied by significant demographic changes led to a sharp increase in breast cancer incidence in Eastern

\footnotetext{
* Correspondence: dusek@iba.muni.cz

'Institute of Biostatistics and Analyses, Masaryk University, Kamenice 126/3, 62500 Brno, Czech Republic

Full list of author information is available at the end of the article
}

European countries including the Czech Republic [2]. Stabilisation of mortality from breast cancer can only be achieved through high quality screening associated with adequate treatment of detected tumours [3]. Efficacy of breast cancer screening by mammography in preventing breast cancer deaths was demonstrated in randomised controlled trials. Meta-analysis of Swedish trials showed breast cancer mortality reduction of $29 \%$ among women aged 50-69 years [4]. Recent meta-analyses stated mortality reduction to be $15 \%$ [5], however, greater protective effect seem to be present in women between 60-69 years [6]. Screening programmes were implemented in

\section{Biomed Central}


many countries worldwide $[7,8]$. The effect indeed persists in real populations: breast cancer mortality decreased by $16 \%$ to $36 \%$ in populations invited to screening and women attending at least one screening examination could decrease their risk of death from breast cancer by $24 \%$ to $48 \%$ [9]. On the other hand, there are also adverse effects associated with breast cancer screening by mammography. Namely these include radiation exposure, pain during mammography, anxiety responses from screening, false-positive and false-negative results, and overdiagnosis [6]. However, there is convincing evidence that, in certain age groups, benefits of mammography screening outweigh its risk. This led to recommendations for screening in United States [10] and Europe [11].

To obtain projected benefits and minimise negative outcomes, the programmes should be implemented with an organised, population-based approach, with quality assurance at all appropriate levels, and in accordance with European Guidelines for Quality Assurance in Breast Cancer Screening and Diagnosis [11,12]. The policy of a screening effort should be documented in a law or an official regulation to qualify as a screening programme [8]. IARC Handbooks of cancer prevention [13] state six characteristics of an organised screening programme: a policy specifying target population, screening method and interval; a defined target population; a team responsible for overseeing screening centres; a decision structure and responsibility for healthcare management; a quality assurance system utilizing relevant data; and monitoring of cancer occurrence in the target population. The highest level of programme organisation, population-based screening, requires that all persons eligible for screening are identified and personally invited to attend a screening examination in each round of screening [8].

The objective of this article is to summarize the implementation and results of the Czech breast cancer screening programme (CBCSP) since 2002. The evaluation of CBCSP is based on a multi-source information system including the monitoring of population cancer burden and early performance indicators of the screening programme. Favourable values of screening performance measures are necessary to have a significant effect on cancer mortality in the future [14]. Therefore, we describe the results of transformation from no-programme opportunistic screening to a non-population based yet highly organised programme by comparison of measured indicators to international guideline targets and published results. To our knowledge, this is one of the first reports from a new EU member state. Compared to previous papers [15-17], this article adds new results on long-term continuous quality improvement after the programme initiation.

\section{Methods}

\section{The Czech Breast Cancer Screening Programme}

In the late $1990 \mathrm{~s}$, mammography was performed at more than 130 facilities and screening examinations were claimed as diagnostic. In 2002 an accreditation programme was launched by a directive of the Czech Ministry of Health with accreditation criteria based on the European Guidelines [11]. The programme is administered by the Breast Cancer Screening Committee at the Ministry of Health. The centres are overseen by the Expert Committee on Breast Imaging (Komise odborník pro mamární diagnostiku).

The CBCSP is a nationwide organized programme, currently performed at 67 regularly monitored accredited centres. The target population was defined as women aged 45-69 years. Since 2010 there is no upper age limit, therefore all women from 45 years of age can attend a biennial mammography screening covered by health insurance. Women are referred to screening mammography by their general practitioners (GPs) or gynaecologists on the basis of preventive check-ups, as there is no established centralised system of direct invitation yet. Women outside the target population (over 40 years of age) can undergo screening mammography (upon direct payment of entire cost of the screening examination) and are therefore included in aggregated statistics.

Mammography is performed in two-views (craniocaudal, mediolateral oblique), independent double reading with consensus is recommended. Both screen-film and digital mammography systems are present. Screening centres also act as breast assessment units, necessary further assessment of the findings (magnification, spot mammography, breast ultrasound, etc.) is provided during the screening visit at the centre (one-day diagnostics). Recall to the screening centre is usually employed in case of a double reading discrepancy or for invasive examinations, including core-cut biopsy (majority performed within one week after screening). For reporting of screening and additional imaging results, the BIRADS system [18] is used and for the evaluation of breast density, typology according to Tabar was included [19]. All of the centres provide core-cut biopsy, special methods (MR mammography and vacuum biopsy) are provided at a narrower network of specialized centres.

Screening programme data are annually consolidated from local databases of screening centres, and are subsequently stored in a secured central database - the Czech Breast Cancer Screening Registry (Figure 1). Official results containing a description of the screening process and performance monitoring are published annually. Feedback for screening centres is provided using annual reporting of performance indicators. 


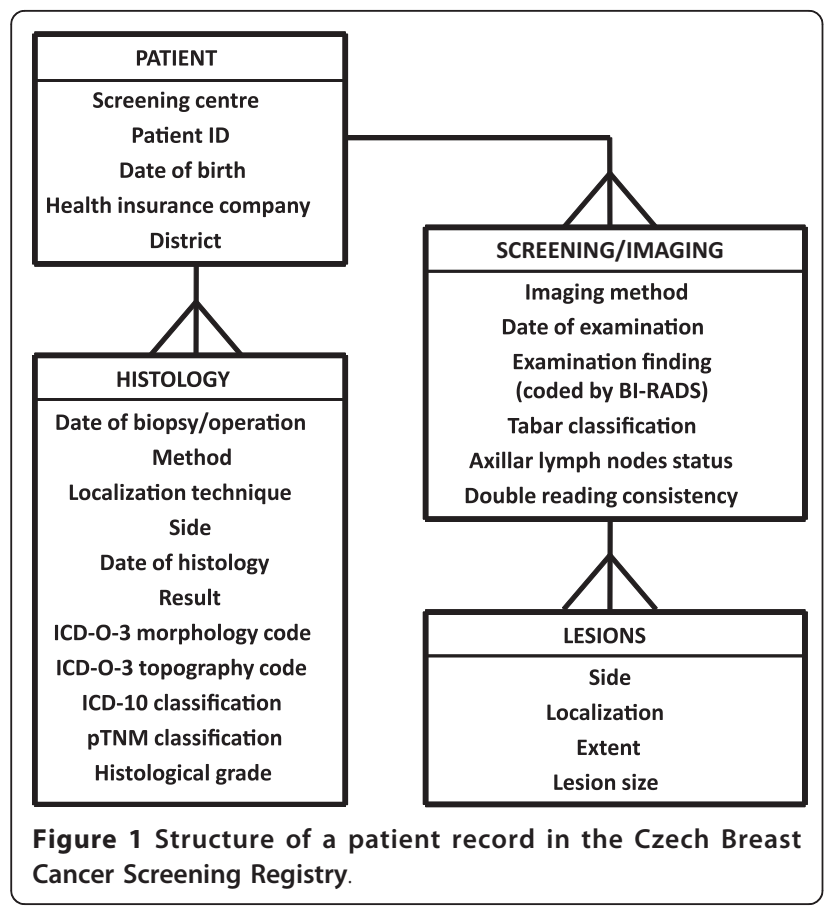

\section{Czech National Cancer Registry}

The Czech National Cancer Registry (CNCR) was established in 1976. With verified $100 \%$ coverage, it contains information on the cancer diagnosis, treatment and survival of all Czech cancer patients. A comprehensive overview of cancer epidemiology in the Czech Republic is available on-line at http://www.svod.cz[20].

\section{Claims data from healthcare payers}

The costs of biennial screening mammography in women from the screening target population are reimbursed by public health insurance in the Czech Republic. Therefore, claims data on mammography are available in data warehouses of healthcare payers provided via centralized exports by the Czech National Reference Centre. These administrative records allow for a description of the utilisation of diagnostic and screening mammography in the Czech female population and to monitor the prevalence of opportunistic screening outside the organised programme.

\section{Data analysis}

Population-based data of CNCR was analysed using standard methods [21] to detect trends in incidence and mortality. The performance of the programme was assessed using the standard set of performance indicators introduced in European Guidelines [11]. The coverage of the target population by screening examination was computed as a ratio between the number of examinations in women aged 45-69 years in previous 24 months and the number of women aged 45-69 in the target population at the end of the period.

Performance of a screening test was assessed using breast cancer detection rates and further assessment rates. Further assessment comprises any additional examination performed until 6 months after screening mammography. Screen-detected cancers comprise all diagnosed breast cancer cases until one year after positive screening. Benign to malignant open biopsy ratio was defined as ratio of the number of women undergoing open biopsy with benign result to the number of women undergoing open biopsy with malignant result. All results were stratified according to the individual screening history of the women: initial or subsequent screening. In order to estimate time-related trends in further assessment rates and detection rates irrespective of changes in age structure and in proportion of initially screened women, standardization [22] was performed. All analyses were performed using Stata/IC 10.1 for Windows [23]. Providers of the utilised data consented with their use for epidemiological research. The study was entirely observational; therefore, no approval from the ethical committee was required.

\section{Results}

\section{Breast cancer burden in the Czech Republic}

The incidence rate of breast cancer has been increasing constantly since the early 1990 s (65.5 cases per 100,000 women in 1990 vs. 122.7 in 2007). On the other hand, the mortality rate was stable during the same period (34.2 cases per 100,000 women in 1990 vs. 36.4 in 2007, Figure 2). The peak value of breast cancer incidence can be observed in 2003 after the introduction of an organised screening programme and again in 2007 when the growing programme was reinforced by a pilot project for the invitation of yet-unscreened women (see discussion for description). It is clearly visible particularly in newly introduced women aged 70-74 years (Figure 3). The continuing rise in incidence after 2002 could be attributed to the screening target population, i.e. women aged 45-69 years. The incidence is stable in younger (30-44 years) and older ( $75+$ years) women.

The rise in incidence rate after 1990 is visible in all postmenopausal age groups. The most recent growth is reduced in the 70-74 age group, due to detection of tumours at a younger age in the screening programme (Figure 4). There is an apparent increase in the proportion of stage I breast cancers which started in the early 1990s and continues after 2002 (Figure 5). This is reflected in increase of early breast cancer rates in the 45-69 age groups. During the same period, we can witness slow decrease in advanced cancer rates (stage III + IV, 50.5 cases per 100,000 women in 1990-1994 vs. 38.1 in 2003-2007, Figure 6). 


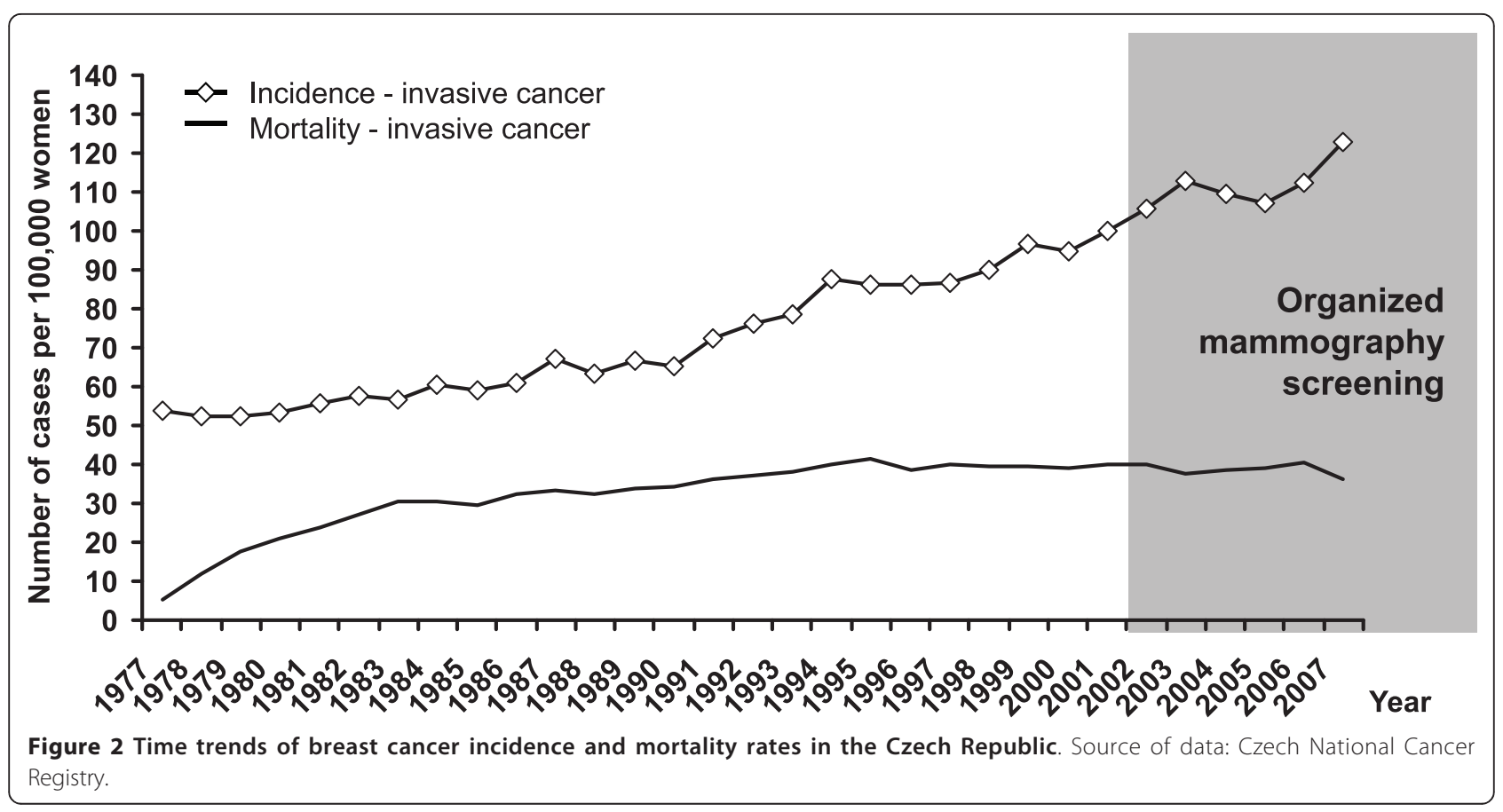

Results of the organised screening programme

The Czech Breast Cancer Screening Registry includes 2,083,285 records on screening episodes between 2002 and 2008. The 24-month coverage by screening mammography steadily increased over these years (Table 1). The coverage in the age group of 45-69 year-olds reached $51.2 \%$ in 2008 . In years $2002-2004$, women attended programme screening examination for the first time (initial screening). Since then, the proportion of subsequent screenings has been constantly rising and reached $66 \%$ in
2008. The age of women attending screenings is also increasing (Table 2). Recruitment is less effective in higher age categories, the coverage decreases from $58.0 \%$ at age $45-49$ to $42.3 \%$ at age $65-69$. The screening programme was not open to elderly women (aged over 70) free of charge before 2010. They were only invited as a part of the pilot project in 2007-2008 and the coverage is therefore only $14.5 \%$ of this age group (Table 3 ).

The crude breast cancer detection rate has been changing a little during first years of the programme

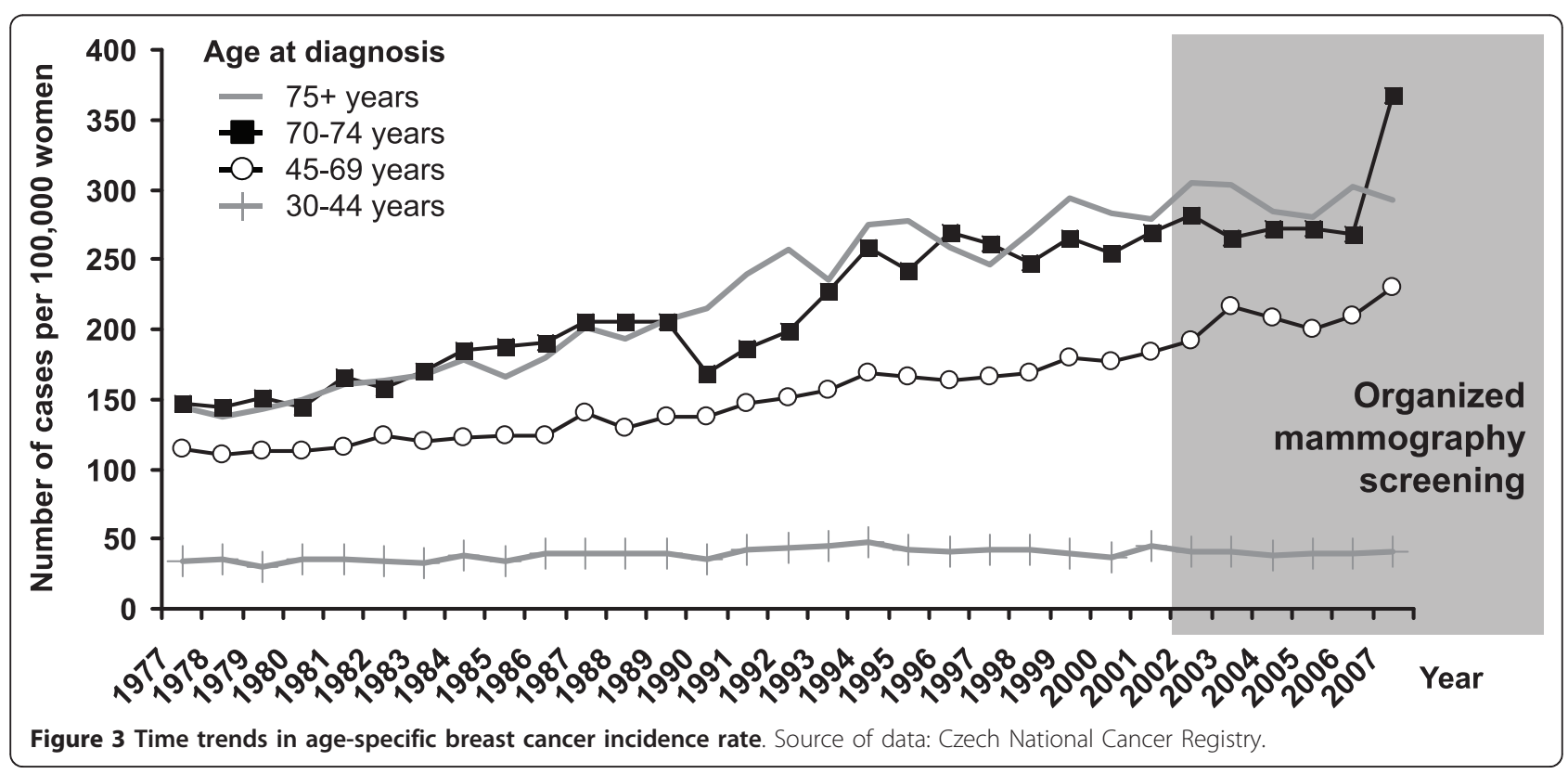




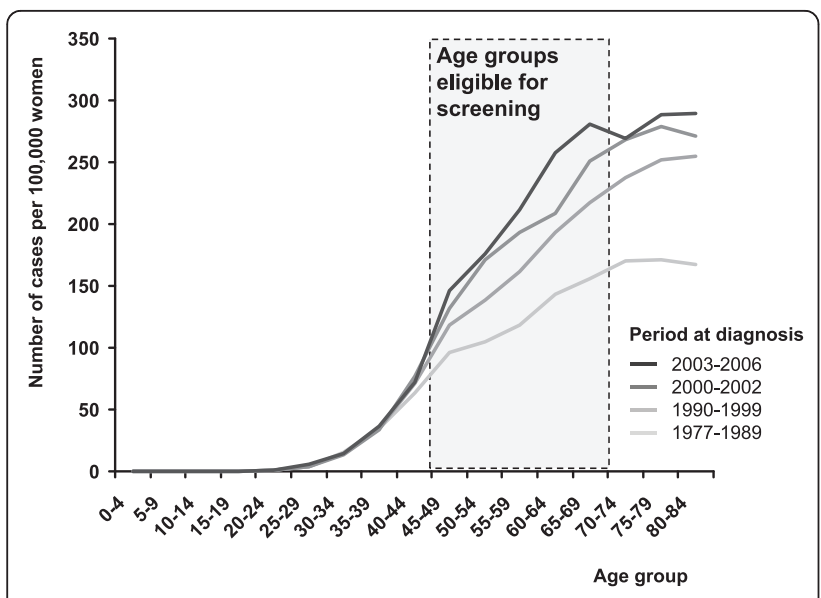

Figure 4 Comparison of age structure of breast cancer patients groups diagnosed in different time periods. Source of data: Czech National Cancer Registry.

(Table 1). Over years and age subgroups, the detection rate was always higher in initially screened women (Tables 4,5 ) than in subsequently screened women (Tables 6,7$)$. The detection rate increases with age in initial (3.1-15.1 detected cases per 1,000 women screened, Table 5) and subsequent (2.1-11.7 detected cases per 1,000 women screened, Table 7) screenings. Bearing the rapidly changing population structure in mind, it is therefore more informative to study development of age-specific rates in initial and subsequent screenings (Figure 7) or summarize them using a standardized rate ratio (Table 1). Both show evidence for constantly improving detection rates after the organisation of the screening programme.
The further assessment rate has been decreasing since 2003 to $12.8 \%$ in 2008 (Table 1 ). This indicator is also subject to trends in age structure and the proportion of subsequent examinations. This rate decreases with age in initial (26.0\%-10.0\%, Table 5) and subsequent (16.2\%$5.7 \%$, Table 7) screenings, being larger in initial screening. Improvement (i.e. decrease) in further assessment rates is clear from both age-specific (Figure 8) and standardized indicators (Table 1 ). Trends in the recall rate are very similar to those in the further assessment rate. Only about $20-30 \%$ of women with positive results of screening are being recalled back to the screening centre. The rest of the women undergo further assessment on the day of the screening visit. The benign to malignant open biopsy ratio is also constantly improving (0.49 in 2002 vs. 0.10 in 2008). The ratio is similar in initially and subsequently screened women. The youngest age groups experience a slightly increased ratio (Tables 5,7 ).

About $30 \%$ of detected breast cancer cases are advanced (TNM stage II+, i.e. involvement of lymph nodes and/or distant metastases) in initial screenings, and this proportion decreases to about $20 \%$ in subsequent screenings (Tables 4, 6). About $90 \%$ of detected cases are invasive in both initial and subsequent screenings. Of these, $60-70 \%$ of the findings are without involvement of lymph nodes (this proportion is higher in subsequent screenings). The primary tumour in about $30-40 \%$ of invasive cases is less than $10 \mathrm{~mm}$ in diameter (this proportion is higher in subsequent screenings).

\section{Discussion}

A recent study [9] reviewed current evidence on the effectiveness of mammography screening in real populations.

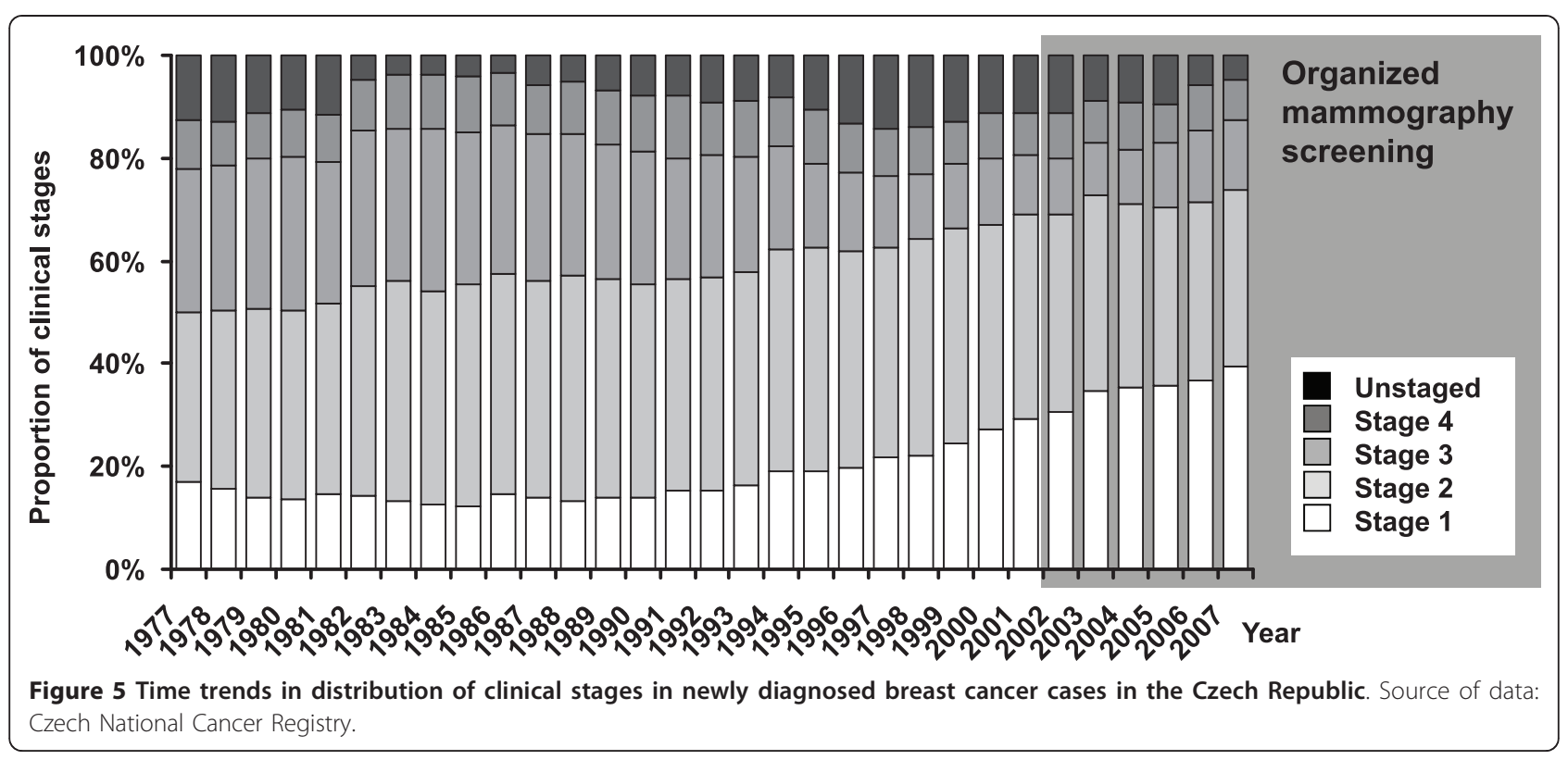




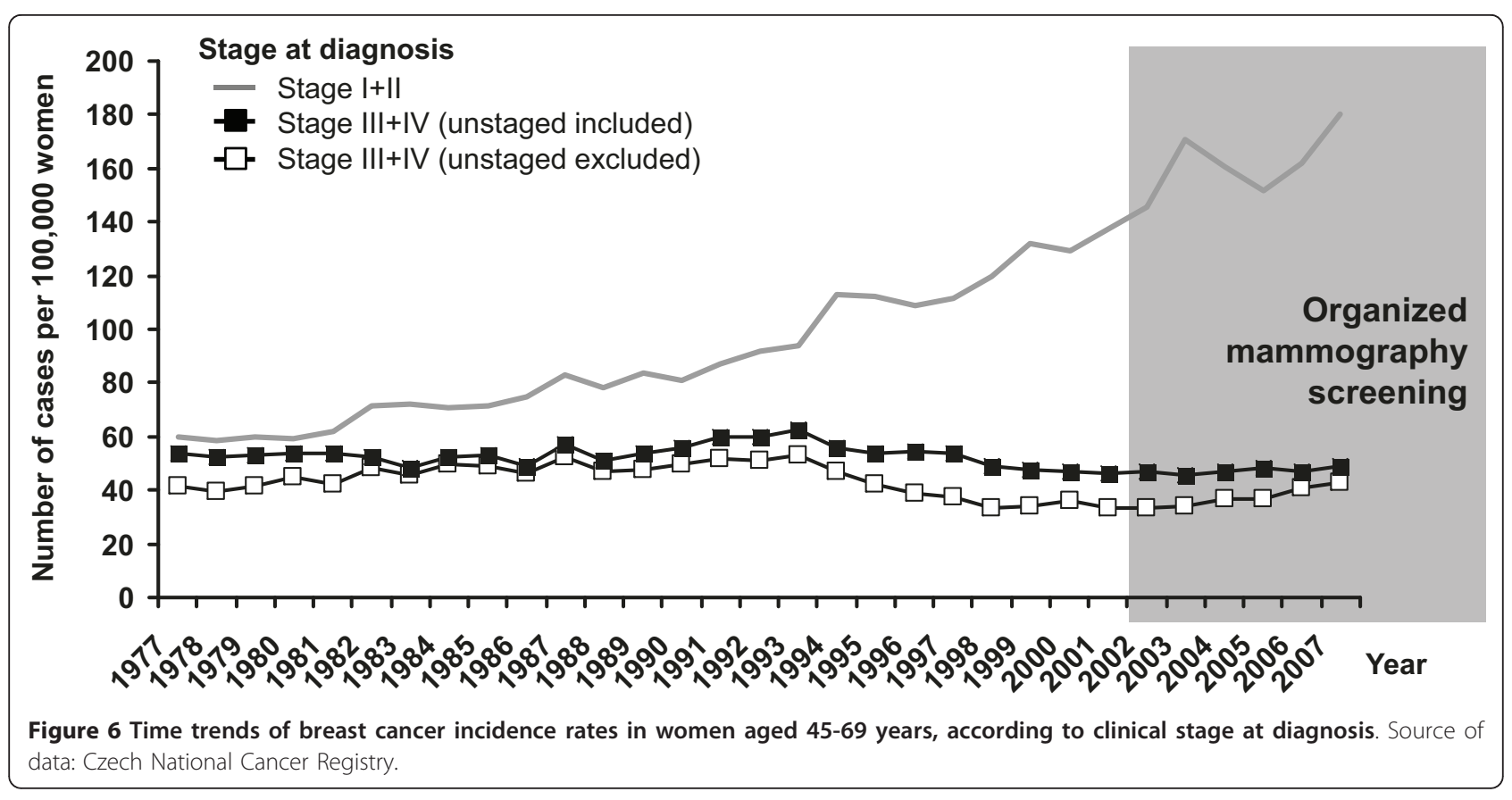

Table 1 Performance indicators of the Czech Breast Cancer Screening Programme, according to year of screening, including all age groups (total)

\begin{tabular}{|c|c|c|c|c|c|c|c|}
\hline & \multicolumn{7}{|c|}{ Year (screening mammography) } \\
\hline & 2002 & 2003 & 2004 & 2005 & 2006 & 2007 & 2008 \\
\hline Number of women screened & 10,055 & 212,537 & 265,217 & 317,194 & 340,564 & 469,299 & 468,419 \\
\hline $\begin{array}{l}\text { Estimate of } 24 \mathrm{~m} \text { coverage by examination } \\
\text { (women aged } 45-69 \text { ) }\end{array}$ & $0.6 \%$ & $13.1 \%$ & $27.9 \%$ & $33.8 \%$ & $38.1 \%$ & $44.8 \%$ & $51.2 \%$ \\
\hline Number of women with detected breast cancer & 48 & 1,053 & 1,250 & 1,445 & 1,570 & 2,542 & 2,128 \\
\hline Breast cancer detection rate & 4.8 & 5.0 & 4.7 & 4.6 & 4.6 & 5.4 & 4.5 \\
\hline Standardized ratio (reference year 2008) & 0.81 & 0.83 & 0.80 & 0.85 & 0.96 & 0.97 & 1.00 \\
\hline Number of women undergoing further assessment & 1,768 & 46,976 & 57,925 & 56,850 & 53,580 & 63,415 & 60,025 \\
\hline Further assessment rate & $17.6 \%$ & $22.1 \%$ & $21.8 \%$ & $17.9 \%$ & $15.7 \%$ & $13.5 \%$ & $12.8 \%$ \\
\hline Standardized ratio (reference year 2008) & 0.90 & 1.20 & 1.21 & 1.14 & 1.10 & 1.01 & 1.00 \\
\hline Number of women recalled for further assessment & 557 & 12,095 & 11,725 & 11,931 & 10,429 & 13,977 & 12,955 \\
\hline Recall rate & $5.5 \%$ & $5.7 \%$ & $4.4 \%$ & $3.8 \%$ & $3.1 \%$ & $3.0 \%$ & $2.8 \%$ \\
\hline Women undergoing open biopsy - benign result & 21 & 504 & 347 & 285 & 194 & 249 & 173 \\
\hline Women undergoing open biopsy - malignant result & 43 & 867 & 1,021 & 1,259 & 1,347 & 2,149 & 1,794 \\
\hline Benign to malignant open biopsy ratio & 0.49 & 0.58 & 0.34 & 0.23 & 0.14 & 0.12 & 0.10 \\
\hline $\begin{array}{l}\text { Number of women with detected breast cancer (cases preceded by neoadjuvant } \\
\text { therapy excluded) }\end{array}$ & 48 & 1,031 & 1,212 & 1,400 & 1,522 & 2,470 & 2,039 \\
\hline Advanced cases (TNM II) & 17 & 331 & 390 & 440 & 439 & 652 & 525 \\
\hline Advanced cases proportion & $35.4 \%$ & $32.1 \%$ & $32.2 \%$ & $31.4 \%$ & $28.8 \%$ & $26.4 \%$ & $25.7 \%$ \\
\hline Invasive cases & 41 & 933 & 1,097 & 1,283 & 1,370 & 2,211 & 1,831 \\
\hline Invasive cases proportion & $85.4 \%$ & $90.5 \%$ & $90.5 \%$ & $91.6 \%$ & $90.0 \%$ & $89.5 \%$ & $89.8 \%$ \\
\hline Node-negative invasive cases & 27 & 572 & 700 & 840 & 905 & 1,442 & 1,218 \\
\hline Proportion among invasive & $65.9 \%$ & $61.3 \%$ & $63.8 \%$ & $65.5 \%$ & $66.1 \%$ & $65.2 \%$ & $66.5 \%$ \\
\hline Invasive $\leq 10 \mathrm{~mm}$ cases & 11 & 312 & 360 & 460 & 504 & 770 & 651 \\
\hline Proportion among invasive & $26.8 \%$ & $33.4 \%$ & $32.8 \%$ & $35.9 \%$ & $36.8 \%$ & $34.8 \%$ & $35.6 \%$ \\
\hline
\end{tabular}


Table 2 Time trends in basic characteristics of the population attending the screening programme

\begin{tabular}{|c|c|c|c|c|c|c|c|c|}
\hline \multirow[t]{2}{*}{ Year screened } & \multicolumn{2}{|c|}{ NUMBER OF WOMEN SCREENED } & \multirow[t]{2}{*}{ Proportion subsequent } & \multicolumn{5}{|c|}{ AGE SCREENED } \\
\hline & Initial & Subsequent & & $\begin{array}{c}5^{\text {th }} \\
\text { percentile }\end{array}$ & $\begin{array}{c}25^{\text {th }} \\
\text { percentile }\end{array}$ & Median & $\begin{array}{c}75^{\text {th }} \\
\text { percentile }\end{array}$ & $\begin{array}{c}95^{\text {th }} \\
\text { percentile }\end{array}$ \\
\hline 2002 & 10,055 & 0 & $0.0 \%$ & 45.6 & 49.2 & 53.8 & 59.0 & 66.5 \\
\hline 2003 & 212,514 & 23 & $0.0 \%$ & 45.7 & 49.4 & 53.9 & 59.3 & 66.7 \\
\hline 2004 & 258,635 & 6,582 & $2.5 \%$ & 45.4 & 49.4 & 54.2 & 59.7 & 66.9 \\
\hline 2005 & 220,897 & 96,297 & $30.4 \%$ & 45.5 & 50.0 & 54.9 & 60.3 & 67.1 \\
\hline 2006 & 170,717 & 169,847 & $49.9 \%$ & 45.5 & 50.1 & 55.1 & 60.5 & 67.2 \\
\hline 2007 & 232,509 & 236,790 & $50.5 \%$ & 45.3 & 50.9 & 56.9 & 63.2 & 70.6 \\
\hline 2008 & 159,273 & 309,146 & $66.0 \%$ & 45.3 & 50.6 & 56.1 & 61.6 & 68.0 \\
\hline
\end{tabular}

The authors identified reports from eight European countries, where mammography screening lead to an eventual decrease in breast cancer mortality. National programmes included Finland [24], Iceland [25], the Netherlands [26] and the United Kingdom [27]. Regionally organised programmes included Denmark [28], Italy [29], Spain [30] and Sweden [31,32]. All of these countries implemented organised screening programmes in the 1980s or early 1990s. Organised screening policies in these countries include the specification of covered age groups, screening interval and detection methods [7]. Programmes include quality assurance systems [33] that utilise data on screening process and also have access to cancer registry data [34].
The CBCSP has been implemented to comprise such organisational aspects, as recommended by the IARC working group. We made comprehensive use of three valuable data sources (cancer registry, cancer screening registry, and the data warehouse of healthcare payers) to continuously monitor the success of the programme. The following discussion compares observed values of early performance indicators with published results and European Guidelines targets [11], which are based on the results of randomized trials and successful screening programmes.

\section{Epidemiology}

In addition to the performance monitoring, the Czech screening programme is supported with highly

Table 3 Performance indicators of the Czech Breast Cancer Screening Programme, according to age group, women screened in 2008 (total)

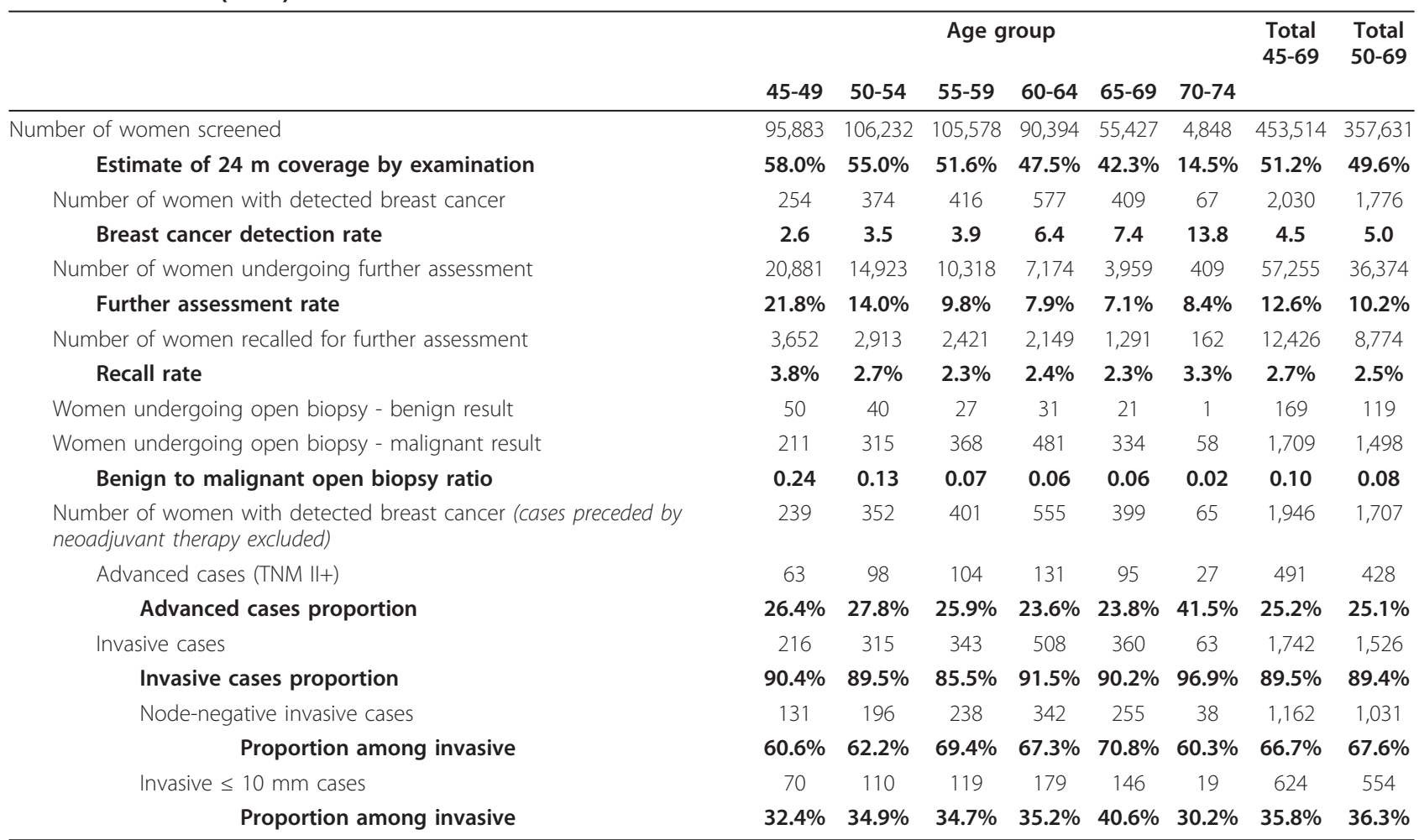


Table 4 Performance indicators of the Czech Breast Cancer Screening Programme, according to year of screening, including all age groups (initial screening)

\begin{tabular}{|c|c|c|c|c|c|c|c|}
\hline & \multicolumn{7}{|c|}{ Year (screening mammography) } \\
\hline & 2002 & 2003 & 2004 & 2005 & 2006 & 2007 & 2008 \\
\hline Number of women screened & 10,055 & 212,514 & 258,635 & 220,897 & 170,717 & 232,509 & 159,273 \\
\hline Number of women with detected breast cancer & 48 & 1,053 & 1,220 & 1,153 & 935 & 1,662 & 974 \\
\hline Breast cancer detection rate & 4.8 & 5.0 & 4.7 & 5.2 & 5.5 & 7.1 & 6.1 \\
\hline Number of women undergoing further assessment & 1,768 & 46,973 & 56,961 & 44,919 & 33,135 & 39,921 & 30,239 \\
\hline Further assessment rate & $17.6 \%$ & $22.1 \%$ & $22.0 \%$ & $20.3 \%$ & $19.4 \%$ & $17.2 \%$ & $19.0 \%$ \\
\hline Number of women recalled for further assessment & 557 & 12,095 & 11,535 & 9,735 & 6,496 & 8,888 & 6,246 \\
\hline Recall rate & $5.5 \%$ & $5.7 \%$ & $4.5 \%$ & $4.4 \%$ & $3.8 \%$ & $3.8 \%$ & $3.9 \%$ \\
\hline Women undergoing open biopsy - benign result & 21 & 504 & 343 & 226 & 135 & 166 & 90 \\
\hline Women undergoing open biopsy - malignant result & 43 & 867 & 992 & 994 & 787 & 1,382 & 784 \\
\hline Benign to malignant open biopsy ratio & 0.49 & 0.58 & 0.35 & 0.23 & 0.17 & 0.12 & 0.11 \\
\hline $\begin{array}{l}\text { Number of women with detected breast cancer (cases preceded by neoadjuvant } \\
\text { therapy excluded) }\end{array}$ & 48 & 1,031 & 1,182 & 1,116 & 905 & 1,610 & 924 \\
\hline Advanced cases (TNM II+) & 17 & 331 & 384 & 367 & 284 & 465 & 277 \\
\hline Advanced cases proportion & $35.4 \%$ & $32.1 \%$ & $32.5 \%$ & $32.9 \%$ & $31.4 \%$ & $28.9 \%$ & $30.0 \%$ \\
\hline Invasive cases & 41 & 933 & 1,072 & 1,023 & 823 & 1,459 & 850 \\
\hline Invasive cases proportion & $85.4 \%$ & $90.5 \%$ & $90.7 \%$ & $91.7 \%$ & $90.9 \%$ & $90.6 \%$ & $92.0 \%$ \\
\hline Node-negative invasive cases & 27 & 572 & 682 & 644 & 525 & 909 & 535 \\
\hline Proportion among invasive & $65.9 \%$ & $61.3 \%$ & $63.6 \%$ & $63.0 \%$ & $63.8 \%$ & $62.3 \%$ & $62.9 \%$ \\
\hline Invasive $\leq 10 \mathrm{~mm}$ cases & 11 & 312 & 350 & 348 & 288 & 441 & 275 \\
\hline Proportion among invasive & $26.8 \%$ & $33.4 \%$ & $32.6 \%$ & $34.0 \%$ & $35.0 \%$ & $30.2 \%$ & $32.4 \%$ \\
\hline
\end{tabular}

Table 5 Performance indicators of the Czech Breast Cancer Screening Programme, according to age group, women screened in 2008 (initial screening)

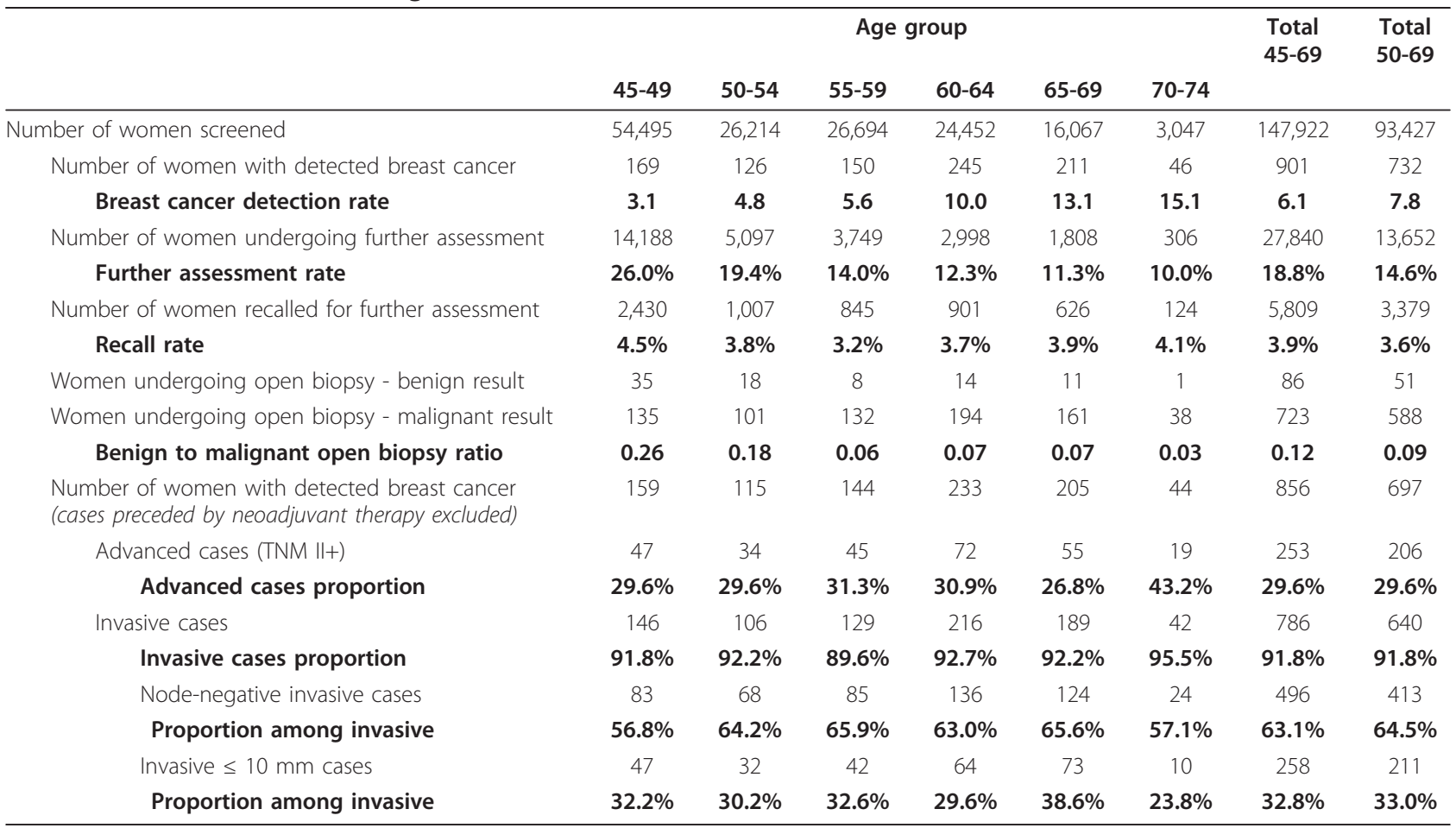


Table 6 Performance indicators of the Czech Breast Cancer Screening Programme, according to year of screening, including all age groups (subsequent screening)

\begin{tabular}{|c|c|c|c|c|c|}
\hline & \multicolumn{5}{|c|}{ Year (screening mammography) } \\
\hline & 2004 & 2005 & 2006 & 2007 & 2008 \\
\hline Number of women screened & 6,582 & 96,297 & 169,847 & 236,790 & 309,146 \\
\hline Number of women with detected breast cancer & 30 & 292 & 635 & 880 & 1,154 \\
\hline Breast cancer detection rate & 4.6 & 3.0 & 3.7 & 3.7 & 3.7 \\
\hline Number of women undergoing further assessment & 964 & 11,931 & 20,445 & 23,494 & 29,786 \\
\hline Further assessment rate & $14.6 \%$ & $12.4 \%$ & $12.0 \%$ & $9.9 \%$ & $9.6 \%$ \\
\hline Number of women recalled for further assessment & 190 & 2,196 & 3,933 & 5,089 & 6,709 \\
\hline Recall rate & $2.9 \%$ & $2.3 \%$ & $2.3 \%$ & $2.1 \%$ & $2.2 \%$ \\
\hline Women undergoing open biopsy - benign result & 4 & 59 & 59 & 83 & 83 \\
\hline Women undergoing open biopsy - malignant result & 29 & 265 & 560 & 767 & 1,010 \\
\hline Benign to malignant open biopsy ratio & 0.14 & 0.22 & 0.11 & 0.11 & 0.08 \\
\hline Number of women with detected breast cancer (cases preceded by neoadjuvant therapy excluded) & 30 & 284 & 617 & 860 & 1,115 \\
\hline Advanced cases (TNM II+) & 6 & 73 & 155 & 187 & 248 \\
\hline Advanced cases proportion & $20.0 \%$ & $25.7 \%$ & $25.1 \%$ & $21.7 \%$ & $22.2 \%$ \\
\hline Invasive cases & 25 & 260 & 547 & 752 & 981 \\
\hline Invasive cases proportion & $83.3 \%$ & $91.5 \%$ & $88.7 \%$ & $87.4 \%$ & $88.0 \%$ \\
\hline Node-negative invasive cases & 18 & 196 & 380 & 533 & 683 \\
\hline Proportion among invasive & $72.0 \%$ & $75.4 \%$ & $69.5 \%$ & $70.9 \%$ & $69.6 \%$ \\
\hline Invasive $\leq 10 \mathrm{~mm}$ cases & 10 & 112 & 216 & 329 & 376 \\
\hline Proportion among invasive & $40.0 \%$ & $43.1 \%$ & $39.5 \%$ & $43.8 \%$ & $38.3 \%$ \\
\hline
\end{tabular}

Table 7 Performance indicators of the Czech Breast Cancer Screening Programme, according to age group, women screened in 2008 (subsequent screening)

\begin{tabular}{|c|c|c|c|c|c|c|c|c|}
\hline & \multicolumn{6}{|c|}{ Age group } & \multirow{2}{*}{$\begin{array}{l}\text { Total } \\
45-69\end{array}$} & \multirow{2}{*}{$\begin{array}{l}\text { Total } \\
50-69\end{array}$} \\
\hline & $45-49$ & $50-54$ & $55-59$ & $60-64$ & $65-69$ & $70-74$ & & \\
\hline Number of women screened & 41,388 & 80,018 & 78,884 & 65,942 & 39,360 & 1,801 & 305,592 & 264,204 \\
\hline Number of women with detected breast cancer & 85 & 248 & 266 & 332 & 198 & 21 & 1,129 & 1,044 \\
\hline Breast cancer detection rate & 2.1 & 3.1 & 3.4 & 5.0 & 5.0 & 11.7 & 3.7 & 4.0 \\
\hline Number of women undergoing further assessment & 6,693 & 9,826 & 6,569 & 4,176 & 2,151 & 103 & 29,415 & 22,722 \\
\hline Further assessment rate & $16.2 \%$ & $12.3 \%$ & $8.3 \%$ & $6.3 \%$ & $5.5 \%$ & $5.7 \%$ & $9.6 \%$ & $8.6 \%$ \\
\hline Number of women recalled for further assessment & 1,222 & 1,906 & 1,576 & 1,248 & 665 & 38 & 6,617 & 5,395 \\
\hline Recall rate & $3.0 \%$ & $2.4 \%$ & $2.0 \%$ & $1.9 \%$ & $1.7 \%$ & $2.1 \%$ & $2.2 \%$ & $2.0 \%$ \\
\hline Women undergoing open biopsy - benign result & 15 & 22 & 19 & 17 & 10 & 0 & 83 & 68 \\
\hline Women undergoing open biopsy - malignant result & 76 & 214 & 236 & 287 & 173 & 20 & 986 & 910 \\
\hline Benign to malignant open biopsy ratio & 0.20 & 0.10 & 0.08 & 0.06 & 0.06 & 0.00 & 0.08 & 0.07 \\
\hline $\begin{array}{l}\text { Number of women with detected breast cancer } \\
\text { (cases preceded by neoadjuvant therapy excluded) }\end{array}$ & 80 & 237 & 257 & 322 & 194 & 21 & 1,090 & 1,010 \\
\hline Advanced cases (TNM II+) & 16 & 64 & 59 & 59 & 40 & 8 & 238 & 222 \\
\hline Advanced cases proportion & $20.0 \%$ & $27.0 \%$ & $23.0 \%$ & $18.3 \%$ & $20.6 \%$ & $38.1 \%$ & $21.8 \%$ & $22.0 \%$ \\
\hline Invasive cases & 70 & 209 & 214 & 292 & 171 & 21 & 956 & 886 \\
\hline Invasive cases proportion & $87.5 \%$ & $88.2 \%$ & $83.3 \%$ & $90.7 \%$ & $88.1 \%$ & $100.0 \%$ & $87.7 \%$ & $87.7 \%$ \\
\hline Node-negative invasive cases & 48 & 128 & 153 & 206 & 131 & 14 & 666 & 618 \\
\hline Proportion among invasive & $68.6 \%$ & $61.2 \%$ & $71.5 \%$ & $70.5 \%$ & $76.6 \%$ & $66.7 \%$ & $69.7 \%$ & $69.8 \%$ \\
\hline Invasive $\leq 10 \mathrm{~mm}$ cases & 23 & 78 & 77 & 115 & 73 & 9 & 366 & 343 \\
\hline Proportion among invasive & $32.9 \%$ & $37.3 \%$ & $36.0 \%$ & $39.4 \%$ & $42.7 \%$ & $42.9 \%$ & $38.3 \%$ & $38.7 \%$ \\
\hline
\end{tabular}




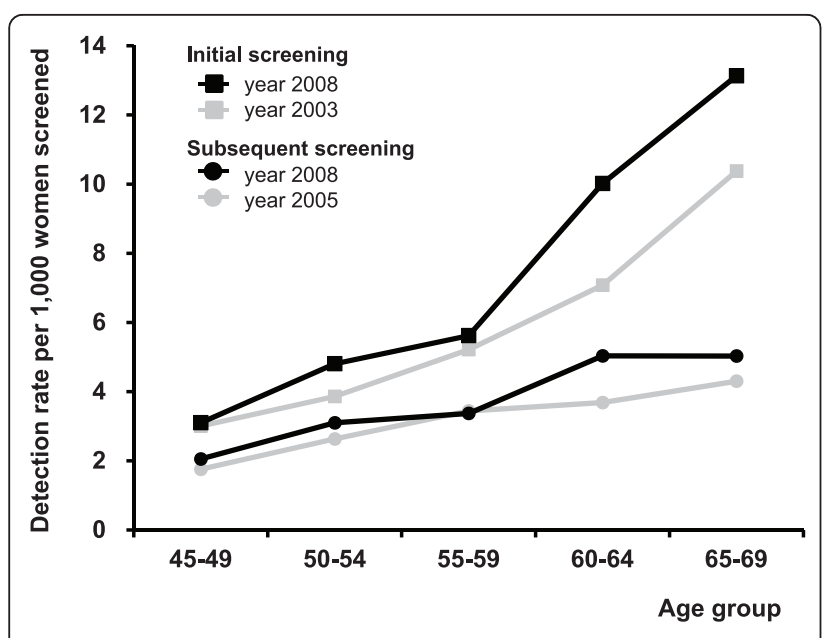

Figure 7 Breast cancer detection rate: age-specific comparison of time periods.

representative epidemiology cancer registry covering the whole population since 1977. Breast cancer incidence has been rising steadily since 1980s. However, further increase in mortality has been arrested after 1995, similarly to other member states of the European Union [3]. The stabilized breast cancer mortality in the Czech Republic can be at least partially attributed to the improving stage distribution of newly diagnosed breast cancer cases and mild decrease in rate of advanced tumours. Nevertheless, part of the increase in early tumours rate is attributable to overdiagnosis - screendetected cancers that would not have surfaced clinically during the woman's lifetime [35]. Estimate of the proportion of overdiagnosed tumours ranges to over $50 \%$ [36]; however, most of the estimates vary from $1 \%$ to $10 \%$ [6]. Very gradual expansion of opportunistic and organised screening does not yet allow us to estimate

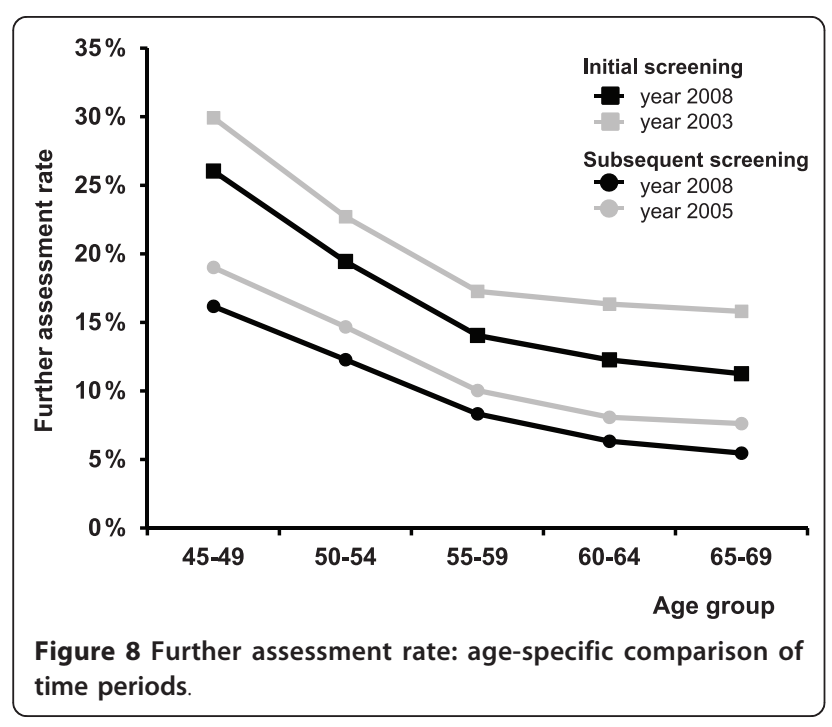

extent of overdiagnosis precisely using epidemiology data; therefore, we have concentrated on assessment of early performance indicators. As their values of detection rates and DCIS proportion comply with European Guidelines targets quite well (see bellow), we do not assume overdiagnosis to markedly excess values seen in clinical and epidemiological studies abroad.

\section{Coverage}

The current Czech system of recruitment through GPs or gynaecologists, reinforced by media campaigns and recall for subsequent screenings by screening centres was able to achieve a modest coverage of $50 \%$. The advantage of this setup is the primary care physician's full knowledge of the patient's medical history and preferences, which enables the proper tailoring of an individual preventive strategy. Nevertheless, participation rates in successful population-based programmes approach the European Guidelines target of 70\% (e.g. Spain [37], United Kingdom [38], Denmark [39]), or even exceed them (Finland [40]). However, the invitation may also fail to achieve the stated target (e.g. decentralized invitation in Hungary [16], invitation without appointment in Luxembourg [41]) - it is therefore necessary to properly plan, implement and monitor the invitation process.

\section{Pilot project}

That is why in 2007-2008 a pilot project of centralised invitation of non-attending women was undertaken. The project was carried out by the General Health Insurance Company (GHIC). GHIC is the principal provider of health insurance in the Czech Republic, with more than 6.5 million clients (about two thirds of the Czech population). A total number of 598,637 women aged between 45 and 74 years were invited for screening mammography (the invited women had not undergone mammography examination during the last three years). The women invited to the pilot project were screened between July 2007 and February 2008. Overall, 107,264 women (i.e., $18 \%$ of those invited) were screened at 60 mammography screening facilities. As regards the target population (45-69 years), 491,294 women were invited and $16.4 \%$ of them were screened. Participation rate was higher in older women (24.7\%).

Despite the relatively low participation rate in the project itself, the project helped to substantially increase coverage in the target population (from 38.1\% in 2006 to $51.2 \%$ in 2008 ), especially in elder women. Furthermore, the pilot project also invited women aged 70-74 and the outcomes of the screening in this group are visible in the epidemiology data. The pilot project confirmed a high sensitivity and specificity of mammography in these elderly groups and led to the 
extension of the age groups targeted by the Czech screening programme in 2010.

\section{Opportunistic activities}

Screening activities occurring outside the programme or before its inception are referred to as 'opportunistic' screening. Opportunistic screening may fail to exploit the full potential of mammography to prevent deaths from breast cancer [42]. A possible explanation includes less sensitivity [43] and subsequently less-favourable prognostic features of detected tumours [44]. It is less cost-effective, mainly due to higher cost of diagnostic mammography and overuse of additional imaging in an unorganized setting $[45,46]$. Dissemination of organised mammography screening can increase programme coverage [17] and also attract more disadvantaged women [47]. It is therefore advisable to promote the highest level of organisation possible, with close monitoring of performance indicators [14].

Intensified nationwide organisation led to an increase in opportunistic mammography activities in Hungary [17]. Yet Jensen [48] concluded that, in Denmark, women not attending an organised programme did not seek the service elsewhere and proportion of women screened outside the programme was 1-4\% in Danish counties. According to monitoring performed by the Czech healthcare payers, the non-programme screening was quite prevalent in the Czech Republic before the onset of the organized programme. In 2002, the proportion of women undergoing non-programme examination was over $15 \%$ and approached $25 \%$ in some regions. In the following years, the overall proportion has been decreasing below $10 \%$; however, it still remains high in some regions.

\section{Sensitivity of the programme}

Important early indirect measures of test and programme sensitivity include detection rate, stage distribution of detected cancers and incidence of interval cancers $[11,14]$.

The presence of opportunistic screening and gradual recruitment into organised screening make it difficult to estimate incidence rates expected in the target population in the absence of screening (background incidence), which is necessary to interpret detection and interval cancer rates. Anyway, a rough estimate could be acquired by averaging pre-programme breast cancer rates. The resulting ratio of detection rate to background incidence rate in initial screening for women aged 50-69 years is 4.1, which is in accordance with European Guidelines and similar to values observed in European pilot projects [49].

Easily observable measures of stage distribution are defined in European Guidelines. The proportion of advanced tumours and the proportion of small invasive tumours achieved the desirable levels given by European Guidelines. On the other hand, the proportion of nodenegative invasive tumours keeps staying below acceptable level. However, modern pathology techniques may lead to increased detection of node metastases of lesser clinical significance $[50,51]$ and targets might need to be restated in light of the new epidemiological data.

Precise estimation of interval cancer rates has not yet been possible in the Czech screening, due to the nonexisting direct individual link between the cancer registry and the cancer screening registry. Prediction of the rate is possible, e.g. using the Markov model [52], however, we don't consider this approach for continuous monitoring of performance indicators.

\section{Safety and efficiency of the programme}

A specific feature of the CBCSP is one-day diagnostics. Providing final results of a screening examination to the women during the screening visit definitely prevents a great amount of adverse psychological consequences drawn by the screening programme [53] and provides a sufficient level comfort. Yet, it might be quite demanding for the staff of the screening centres and might increase the further assessment rate, because the women are readily available at the screening centre during the mammogram assessment. Indeed, despite the continuous decrease in time, further assessment remains 2-3 times higher than in Western and Northern European countries [54]. Recall rates are nevertheless similar, as only some of women with further assessment are actually recalled back to the screening centre.

The high positive predictive value of further assessment is provided by the successful adoption of preoperative diagnostics with core biopsy. This part of the screening process is reflected by a benign to malignant open biopsy ratio, one of the key indicators in the European Guidelines. Results in the CBCSP achieved the desirable target in the Guidelines and became fully comparable to long operating population-based screening programmes, e.g. in Finland and Italy [40,55].

\section{Conclusions}

The transformation from opportunistic prevention to an organised programme facilitated continuous improvement in the quality of offered mammography screening examinations. Most performance indicators reach targets set by European Guidelines and observed in successful population-based programmes around Europe. This promises effectiveness, safety and efficiency similar to randomized clinical trials, which justifies the enormous investment into programme initiation and operation. The important task now is to implement addressed invitations to the screenings and to institute a system for 
monitoring the impact of cancer screening on population epidemiology, including examination of the possible risk of overdiagnosis.

\section{Acknowledgements and Funding}

The authors want to acknowledge the screening centres, the Institute for Health Informatics and Statistics of the Czech Republic and Czech public health insurance companies, for their excellent cooperation in providing the data necessary for the implementation of the programme's information support.

This work was supported by the Grant Agency of the Czech Ministry of Health (project no. 10650-3)

\section{Author details}

${ }^{1}$ Institute of Biostatistics and Analyses, Masaryk University, Kamenice 126/3, 62500 Brno, Czech Republic. ${ }^{2}$ Department of Radiology, First Faculty of Medicine, Charles University in Prague, U Nemocnice 2, 12808 Prague, Czech Republic. ${ }^{3}$ Association of Czech Breast Radiologists, Roskotova 1717/2, 14044 Prague, Czech Republic. ${ }^{4}$ Department of Radiology, Masaryk Memorial Cancer Institute, Zluty kopec 7, 65653 Brno, Czech Republic. ${ }^{5}$ National Reference Centre, Vinohradska 112, 13000 Prague, Czech Republic.

\section{Authors' contributions}

OM, LB and LD designed and performed the statistical analysis. JD, MS and $\mathrm{HB}$ participated in the design of the study and were responsible for interpretation of the programme results from the radiological viewpoint. DK and PB were responsible for design and administration of the Czech Breast Cancer Screening Registry. PK coordinated providing of healthcare payers data. OM was responsible for coordination of writing of the manuscript. All authors read and approved the final manuscript.

\section{Competing interests}

The authors declare that they have no competing interests.

Received: 22 December 2010 Accepted: 10 May 2011

Published: 10 May 2011

\section{References}

1. Parkin DM, Bray F, Ferlay J, Pisani P: Global cancer statistics, 2002. CA Cancer J Clin 2005, 55:74-108.

2. $\quad$ Dusek L, et al: Czech Cancer Care in Numbers 2008-2009 Praha: Grada Publishing, a.s; 2009

3. Zatonski W, Didkowska J: Closing the gap: cancer in Central and Eastern Europe (CEE). Eur J Cancer 2008, 44:1425-1437.

4. Nystrom $L$, Rutqvist $L E$, Wall $S$, Lindgren $A$, Lindqvist $M$, Ryden $S$, Andersson I, Bjurstam N, Fagerberg G, Frisell J, et al: Breast cance screening with mammography: overview of Swedish randomised trials. Lancet 1993, 341:973-978.

5. Gotzsche PC, Nielsen M: Screening for breast cancer with mammography. Cochrane Database Syst Rev 2009, CD001877.

6. Nelson HD, Tyne K, Naik A, Bougatsos C, Chan BK, Humphrey L: Screening for breast cancer: an update for the U.S. Preventive Services Task Force. Ann Intern Med 2009, 151:727-737, W237-742.

7. Shapiro S, Coleman EA, Broeders M, Codd M, de Koning H, Fracheboud J, Moss S, Paci E, Stachenko S, Ballard-Barbash R: Breast cancer screening programmes in 22 countries: current policies, administration and guidelines. International Breast Cancer Screening Network (IBSN) and the European Network of Pilot Projects for Breast Cancer Screening. Int J Epidemiol 1998, 27:735-742.

8. Karsa L, Anttila A, Ronco G, Ponti A, Malila N, Arbyn M, Segnan N, CastilloBeltran M, Boniol M, Ferlay J, et al: Cancer Screening in the European Union: Report on the implementation of the Council Recommendation on cancer screening Luxembourg: European Communities; 2008

9. Schopper D, de Wolf C: How effective are breast cancer screening programmes by mammography? Review of the current evidence. Eur $J$ Cancer 2009, 45:1916-1923.

10. U.S. Preventive Services Task Force: Screening for breast cancer: U.S. Preventive Services Task Force recommendation statement. Ann Intern Med 2009, 151:716-726, W-236.
11. Perry N, Broeders $M$, de Wolf $C$, Tornberg S, Holland R, von Karsa L,

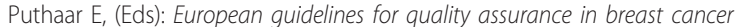
screening and diagnosis, 4th ed Luxembourg: Office for Official Publications of the EC; 2006.

12. Perry N, Broeders M, de Wolf C, Tornberg S, Holland R, von Karsa L: European guidelines for quality assurance in breast cancer screening and diagnosis. Fourth edition-summary document. Ann Oncol 2008 19:614-622.

13. Vainio H, Bianchini F: Breast Cancer Screening Lyon: IARCPress; 2002.

14. Day NE, Williams DR, Khaw KT: Breast cancer screening programmes: the development of a monitoring and evaluation system. Br J Cancer 1989. 59:954-958.

15. Hertl K, Primic-Zakelj M, Zgajnar J, Kocijancic I: Performance of opportunistic breast cancer screening in Slovenia. Neoplasma 2006, 53:237-241.

16. Boncz I, Sebestyen A, Dobrossy L, Pentek Z, Budai A, Kovacs A, Dozsa C, Ember I: The organisation and results of first screening round of the Hungarian nationwide organised breast cancer screening programme. Ann Oncol 2007, 18:795-799.

17. Boncz I, Sebestyen A, Pinter I, Battyany I, Ember I: The effect of an organized, nationwide breast cancer screening programme on non-organized mammography activities. J Med Screen 2008, $15: 14-17$

18. American College of Radiology: Illustrated breast imaging reporting and data system Reston, VA: American College of Radiology; 1998.

19. Gram IT, Funkhouser E, Tabar L: The Tabar classification of mammographic parenchymal patterns. Eur J Radiol 1997, 24:131-136.

20. Epidemiology of Malignant Tumours in the Czech Republic. [http://www. svod.cz/].

21. Jensen O, Parkin DM, MacLennan R, Muir C, Skeet R: Cancer Registration: Principles and Methods Lyon: International Agency for Research on Cancer; 1991

22. Kan L, Olivotto IA, Warren Burhenne LJ, Sickles EA, Coldman AJ: Standardized abnormal interpretation and cancer detection ratios to assess reading volume and reader performance in a breast screening program. Radiology 2000, 215:563-567.

23. StataCorp: Stata Statistical Software: Release 10 College Station, TX StataCorp LP; 2007

24. Sarkeala T, Heinavaara $S$, Anttila A: Organised mammography screening reduces breast cancer mortality: a cohort study from Finland. Int $J$ Cancer 2008, 122:614-619.

25. Gabe R, Tryggvadottir L, Sigfusson BF, Olafsdottir GH, Sigurdsson K, Duffy SW: A case-control study to estimate the impact of the Icelandic population-based mammography screening program on breast cancer death. Acta Radiol 2007, 48:948-955.

26. Otto SJ, Fracheboud J, Looman CW, Broeders MJ, Boer R, Hendriks JH, Verbeek $\mathrm{AL}_{\mathrm{L}}$ de Koning $\mathrm{HJ}$ : Initiation of population-based mammography screening in Dutch municipalities and effect on breast-cancer mortality: a systematic review. Lancet 2003, 361:1411-1417.

27. Blanks RG, Moss SM, McGahan CE, Quinn MJ, Babb PJ: Effect of NHS breast screening programme on mortality from breast cancer in England and Wales, 1990-8: comparison of observed with predicted mortality. BMJ 2000, 321:665-669

28. Olsen AH, Njor SH, Vejborg I, Schwartz W, Dalgaard P, Jensen MB, Tange UB, Blichert-Toft M, Rank F, Mouridsen H, Lynge E: Breast cancer mortality in Copenhagen after introduction of mammography screening: cohort study. BMJ 2005, 330:220.

29. Paci E, Coviello E, Miccinesi G, Puliti D, Cortesi L, De Lisi V, Ferretti S, Mangone L, Perlangeli $V$, Ponti A, et al: Evaluation of service mammography screening impact in Italy. The contribution of hazard analysis. Eur J Cancer 2008, 44:858-865.

30. Ascunce EN, Moreno-Iribas C, Barcos Urtiaga A, Ardanaz E, Ederra Sanz M, Castilla J, Egues N: Changes in breast cancer mortality in Navarre (Spain) after introduction of a screening programme. J Med Screen 2007, 14:14-20.

31. SOSSEG: Reduction in breast cancer mortality from the organized service screening with mammography: 1. Further confirmation with extended data. Cancer Epidemiol Biomarkers Prev 2006, 15:45-51.

32. SOSSEG: Reduction in breast cancer mortality from the organised service screening with mammography: 2 . Validation with alternative analytic methods. Cancer Epidemiol Biomarkers Prev 2006, 15:52-56. 
33. Klabunde C, Bouchard F, Taplin S, Scharpantgen A, Ballard-Barbash R: Quality assurance for screening mammography: an international comparison. J Epidemiol Community Health 2001, 55:204-212.

34. Klabunde CN, Sancho-Garnier H, Broeders M, Thoresen S, Rodrigues VJ, Ballard-Barbash R: Quality assurance for screening mammography data collection systems in 22 countries. Int J Technol Assess Health Care 2001, 17:528-541.

35. Day NE: Overdiagnosis and breast cancer screening. Breast Cancer Res 2005, 7:228-229.

36. Jorgensen K, Gotzsche PC: Overdiagnosis in publicly organised mammography screening programmes: systematic review of incidence trends. Bmj 2009, 339:b2587.

37. Ascunce N, Salas D, Zubizarreta R, Almazan R, Ibanez J, Ederra M: Cancer screening in Spain. Ann Oncol 2010, 21(Suppl 3):iii43-51.

38. Bennett RL, Blanks RG, Patnick J, Moss SM: Results from the UK NHS Breast Screening Programme 2000-05. J Med Screen 2007, 14:200-204.

39. Vejborg I, Olsen AH, Jensen MB, Rank F, Tange UB, Lynge E: Early outcome of mammography screening in Copenhagen 1991-99. J Med Screen 2002, 9:115-119.

40. Sarkeala T, Anttila A, Forsman H, Luostarinen T, Saarenmaa I, Hakama M: Process indicators from ten centres in the Finnish breast cancer screening programme from 1991 to 2000. Eur J Cancer 2004, 40:2116-2125

41. Autier P, Shannoun F, Scharpantgen A, Lux C, Back C, Severi G, Steil S, Hansen-Koenig D: A breast cancer screening programme operating in a liberal health care system: the Luxembourg Mammography Programme, 1992-1997. Int J Cancer 2002, 97:828-832.

42. Oberaigner W, Buchberger W, Frede T, Knapp R, Marth C, Siebert U: Breast cancer incidence and mortality in Tyrol/Austria after fifteen years of opportunistic mammography screening. BMC Public Health 10:86.

43. Bihrmann K, Jensen A, Olsen AH, Njor S, Schwartz W, Vejborg I, Lynge E: Performance of systematic and non-systematic ('opportunistic') screening mammography: a comparative study from Denmark. J Med Screen 2008, 15:23-26.

44. Bordoni A, Probst-Hensch NM, Mazzucchelli L, Spitale A: Assessment of breast cancer opportunistic screening by clinical-pathological indicators: a population-based study. Br J Cancer 2009, 101:1925-1931.

45. de Gelder R, Bulliard JL, de Wolf C, Fracheboud J, Draisma G, Schopper D, de Koning HJ: Cost-effectiveness of opportunistic versus organised mammography screening in Switzerland. Eur J Cancer 2009, 45:127-138.

46. Bulliard JL, Ducros C, Jemelin C, Arzel B, Fioretta G, Levi F: Effectiveness of organised versus opportunistic mammography screening. Ann Oncol 2009, 20:1199-1202.

47. Chamot E, Charvet Al, Perneger TV: Who gets screened, and where: a comparison of organised and opportunistic mammography screening in Geneva, Switzerland. Eur J Cancer 2007, 43:576-584.

48. Jensen A, Olsen AH, von Euler-Chelpin M, Helle Njor S, Vejborg I, Lynge E: Do nonattenders in mammography screening programmes seek mammography elsewhere? Int J Cancer 2005, 113:464-470.

49. Broeders MJ, Scharpantgen A, Ascunce N, Gairard B, Olsen AH, Mantellini P, Mota TC, Van Limbergen E, Seradour B, Ponti A, et al: Comparison of early performance indicators for screening projects within the European Breast Cancer Network: 1989-2000. Eur J Cancer Prev 2005, 14:107-116.

50. Sahin AA, Guray M, Hunt KK: Identification and biologic significance of micrometastases in axillary lymph nodes in patients with invasive breast cancer. Arch Pathol Lab Med 2009, 133:869-878.

51. Madsen AH, Jensen AR, Christiansen P, Garne JP, Cold S, Ewertz M, Overgaard J: Does the introduction of sentinel node biopsy increase the number of node positive patients with early breast cancer? A population based study form the Danish Breast Cancer Cooperative Group. Acta Oncol 2008, 47:239-247.

52. Chen TH, Kuo HS, Yen MF, Lai MS, Tabar L, Duffy SW: Estimation of sojourn time in chronic disease screening without data on interval cases. Biometrics 2000, 56:167-172.

53. Brett J, Austoker J, Ong G: Do women who undergo further investigation for breast screening suffer adverse psychological consequences? A multi-centre follow-up study comparing different breast screening result groups five months after their last breast screening appointment. J Public Health Med 1998, 20:396-403.
54. Lynge E, Olsen AH, Fracheboud J, Patnick J: Reporting of performance indicators of mammography screening in Europe. Eur J Cancer Prev 2003, 12:213-222.

55. Giordano L, Giorgi D, Piccini P, Stefanini V, Castagno R, Senore C: Time trends of some indicators of mammography screening programmes in Italy, 1996-2003. Epidemiol Prev 2006, 30:17-26.

\section{Pre-publication history}

The pre-publication history for this paper can be accessed here: http://www.biomedcentral.com/1471-2458/11/288/prepub

doi:10.1186/1471-2458-11-288

Cite this article as: Majek et al.: Breast cancer screening in the Czech Republic: time trends in performance indicators during the first seven years of the organised programme. BMC Public Health 2011 11:288.

\section{Submit your next manuscript to BioMed Central and take full advantage of:}

- Convenient online submission

- Thorough peer review

- No space constraints or color figure charges

- Immediate publication on acceptance

- Inclusion in PubMed, CAS, Scopus and Google Scholar

- Research which is freely available for redistribution

Submit your manuscript at www.biomedcentral.com/submit
C) Biomed Central 